\title{
Mechanical Behavior of Glass Ionomer Cements as a Function of Loading Condition and Mixing Procedure
}

\author{
Nicoleta ILIE and Reinhard HICKEL \\ Dental School of the Ludwig-Maximilians University, Munich, Germany \\ Corresponding author, Nicoleta ILIE; E-mail: nicoleta.ilie@dent.med.uni-muenchen.de
}

Received November 27, 2006/Accepted March 8, 2007

With a view to comparing conventional (CGIC) and resin-modified glass ionomer cements (RMGIC) in terms of mechanical properties, these materials were subjected to different loading conditions for evaluation. In addition, this study investigated the assumption that capsulated systems possess superior mechanical properties compared to the hand-mixed systems, owing to the former's better material homogeneity and a more precise adjustment of the powder-liquid ratio.

In view of the aims of this study, the following mechanical properties were determined: strength and modulus of elasticity in flexural test, diametric tensile and compressive strengths, as well as variation of hardness and modulus of elasticity with depth.

In all macroscopic strength tests, the RMGICs performed significantly better than the CGICs. In microhardness evaluation, the differences were levelled out. In particular, the mechanical properties of RMGICs were comparable to those of microfilled and packable composites.

The effect of mixing was closely intertwined with material property. The tested CGICs performed better when they were hand-mixed, whereas RMGICs fared better in the capsulated form.

Keywords: Glass ionomers, Mechanical properties, Mixing systems

\section{INTRODUCTION}

Owing to their numerous outstanding characteristics as a restorative material, glass ionomer cements make a very valuable contribution to daily dental practice. To begin with, glass ionomer cements are the only restorative material capable of forming stable physicochemical bonds to both enamel and dentin $^{1)}$. As a caries-restraining material, they are also capable of sustained, long-term fluoride release $^{2-4)}$. Moreover, other clinical advantages include good biocompatibility, resistance to microleakage $e^{3)}$, as well as low coefficient of thermal expansion ${ }^{5}$.

Nonetheless, conventional glass ionomer cements are not without flaws and failures. They have poor mechanical properties, thus limiting their clinical use as a permanent filling material in the posterior region $^{6,7)}$. The inferior mechanical properties are related to the hardening mechanism which occurs in two distinct stages. The initial short and watersensitive stage occurs within a few minutes after mixing, followed by a slow and long-term hardening process. The latter stage depends on the release of calcium and aluminium cations within the matrix and is susceptible to dehydration. In the initial period of setting, glass ionomer cements are relatively weak in compressive and diametral tensile strengths and show high wear rates ${ }^{8,9}$.

To improve the mechanical characteristics of conventional glass ionomer cements, metal-reinforced glass ionomer cements were developed. Besides an increase in physical strength, the addition of silveramalgam alloy powder to conventional materials also provided radiopacity ${ }^{10)}$. Subsequently, faster setting, high-viscosity conventional glass ionomer cements were developed in the early 1990s for use with the atraumatic restorative treatment in some developing countries $^{11)}$. These so-called viscous or condensable glass ionomer cements set faster and are of higher viscosity because of finer glass particles, anhydrous polyacrylic acids of high molecular weight, and a high powder-to-liquid mixing ratio. The setting reaction, however, is the same as the acid-base reaction typical of conventional glass ionomer cements ${ }^{11}$. In a 6.3-year clinical study by Frencken et al. employing the permanent teeth of young children, they concluded that restorations produced with the atraumatic restorative treatment approach — with high-viscosity glass ionomer - survived longer than those produced with the traditional approach using amalgam $^{12)}$.

Recently, in a bid to improve the mechanical characteristics - especially the poor initial mechanical resistance - of conventional glass ionomer cements, new classes of materials such as resinmodified glass ionomer cements and polyacidmodified composite resins were developed ${ }^{13,14)}$. In particular, the additional light polymerization substantiates the chemical hardening process in the initial phase and thus brings about a significant improvement in mechanical properties.

To further enhance the mechanical properties, defects such as voids and bubbles - stemming from the mixing of cement powder and fluid - must be reduced. In this connection, several manufacturers currently deliver capsulated systems - in addition to 
hand-mixed systems - with a view to improving the handling property of these materials as well as ensuring an exact dosage of the powder-liquid ratio.

The aim of this study was to compare highviscosity conventional and resin-modified glass ionomer cements in terms of their mechanical properties. As such, these materials were subjected to different loading conditions. Further, this study also investigated the assumption that a capsulated system — due to better homogeneity of the material and a more precise adjustment of the powder-liquid ratio - would possess superior mechanical properties in comparison to a hand-mixed system.

\section{MATERIALS AND METHODS}

\section{Materials}

Two high-viscosity conventional glass ionomer cements (CGICs) (Fuji IX and Ionofil Molar) and four resin-modified glass ionomer cements (RMGICs) (Fuji II LC Improved, Photac Fil, Vitremer, and Fuji Fil LC) were compared by determining the following parameters: flexural strength and modulus of elasticity in flexural test, diametric tensile strength, compressive strength, and variation of Vickers hardness and modulus of elasticity with depth. Three of these materials — Fuji IX, Ionofil Molar, and Fuji II LC Improved - are currently available on the market in both forms: capsulated and powder-liquid handmixing systems. Fuji Fil LC was supplied by the manufacturer only as a paste-paste system, whereas all other materials were tested in the capsulated form (Table 1). For all materials, shade A3 was selected.

\section{Flexural strength and modulus of elasticity}

Flexural strength was determined in a three-point bending test $(n=10)$ according to ISO/DIN $4049: 1988^{15)}$. To make bar-shaped specimens, a stainless steel mold (16 $\mathrm{mm}$ length, $2 \mathrm{~mm}$ width, $2 \mathrm{~mm}$ height) was used. The material was pressed between two parallel glass slabs isolated by a strip of transparent foil (US-120 KE, Frasaco, Tettnang, Germany). Samples were polymerized with overlapping irradiation for 20 seconds with a LED curing unit, Freelight 2 (3M ESPE, Seefeld, Germany), on both sides. Cured samples were stored in the mold for 15 minutes in an oven at $37^{\circ} \mathrm{C}$, then ground with 1200-grit silicon carbide grinding paper (LECO, St. Joseph, MI, USA) to remove excess material and edge defects.

After storage for 24 hours in distilled water at $37^{\circ} \mathrm{C}$, the specimens were loaded into a universal testing machine (MCE 2000ST, Quicktest Prüfpartner GmbH, Langenfeld, Germany) for the three-point bending test at a constant crosshead speed of $0.5 \mathrm{~mm} / \mathrm{min}$ until fracture. Distance between the supporting points in the three-point bending test was $12 \mathrm{~mm}$. It should be mentioned that even during the test, the specimens laid in distilled water at room temperature. Modulus of elasticity was determined from the linear part of the force-deflection curve.

\section{Diametric tensile strength}

Using an analogous method, cylindrical specimens (3 $\mathrm{mm}$ height, $6 \mathrm{~mm}$ diameter) were made and stored in a Teflon mold. Specimens were placed between two parallel slabs of the universal testing unit and loaded with axial force at a constant crosshead speed

Table 1 Materials and their mixing systems

\begin{tabular}{|c|c|c|c|c|}
\hline Glass ionomers & Manufacture $r$ & Batch no. & $\begin{array}{l}\text { mixing } \\
\text { System }\end{array}$ & Chemical composition \\
\hline Fuji Fil LC & GC & 0512161 & Paste-Paste & $\begin{array}{l}\text { Polyacrylic acid, } \\
\text { 2-Hydroxyethylmethacrylat } \\
\text { Urethanedimethacrylate } \\
\text { Silicone dioxide } \\
\text { Aluminosilicate glass }\end{array}$ \\
\hline \multirow{2}{*}{ Fuji ॥ LC improved } & \multirow{2}{*}{ GC } & 05101112 & Manual mixing & \multirow{2}{*}{$\begin{array}{l}\text { Polyacrylic acid, } \\
\text { 2-Hydroxyethylmethacrylat } \\
\text { Urethanedimethacrylate } \\
\text { Aluminosilicate glass }\end{array}$} \\
\hline & & 0511211 & Encapsulated & \\
\hline \multirow{2}{*}{ Fuji IX } & \multirow{2}{*}{ GC } & 0512081 & Manual mixing & \multirow{2}{*}{$\begin{array}{l}\text { Polyacrylic acid } \\
\text { Aluminosilicate glass }\end{array}$} \\
\hline & & 0602071 & Encapsulated & \\
\hline Photac Fil & 3M ESPE & 238979 & Encapsulated & $\begin{array}{l}\text { Polyalkenoic acid, } \\
\text { 2-Hydroxyethylmethacrylat } \\
\text { Fluoroaluminosilicate glass }\end{array}$ \\
\hline Vitremer & 3M ESPE & 200512272 & Manual mixing & $\begin{array}{l}\text { Modified polyalkenoic acid } \\
\text { Fluoroaluminosilicate glass }\end{array}$ \\
\hline \multirow{2}{*}{ Ionofil Molar } & \multirow{2}{*}{ VOCO } & 580342 & Manual mixing & \multirow{2}{*}{$\begin{array}{l}\text { Polyacrylic acid } \\
\text { Fluoride silicate glass }\end{array}$} \\
\hline & & 601007 & Encapsulated & \\
\hline
\end{tabular}


of $0.5 \mathrm{~mm} / \mathrm{min}$ until fracture.

Compressive strength

Compressive strength was determined using an analogous method with specimens at $8 \mathrm{~mm}$ height and $4 \mathrm{~mm}$ diameter.

Variation of hardness and modulus of elasticity with depth

To determine the variation of hardness and modulus of elasticity with depth, samples were prepared in an opaque plastic mold (Teflon) of $8 \mathrm{~mm}$ height. The mold was filled in bulk, and the curing unit was applied directly on the sample surface. To analyze the quality of polymerization within the 8-mm-high samples, hardness profiles through the middle of the samples $(n=5)$ were measured. Preparation and storage of samples were as per described above. After storage, the samples were sectioned in the middle prior to testing with a slow-speed diamond saw (Isomet low speed saw, Buehler, Dïsseldorf, Germany) under water and polished with a diamond suspension (mean grain size: $1 \mu \mathrm{m}$ ).

Measurements were made with an automatic microhardness indenter (Fischerscope H100C, Fischer, Sindelfingen, Germany) starting from $0.1 \mathrm{~mm}$ under the surface, with $100-\mu \mathrm{m}$ distance intervals between the measuring points. The test procedure was carried out under controlled force, whereby the test load increased and decreased with constant speed between $0.4 \mathrm{mN}$ and $500 \mathrm{mN}$. Load and penetration depth of the indenter were continuously measured during the load-unload hysteresis.

Universal hardness is defined as the test force divided by the apparent area of the indentation under the applied test force. From a multiplicity of measurements stored in a database supplied by the manufacturer, a conversion factor between Universal hardness and Vickers hardness was calculated and input into a software (WIN-HCU ${ }^{\circledR}$, Fischer, Sindelfingen, Germany), so that measurement results were indicated in the more familiar Vickers hardness units. As for the indentation modulus, it was calculated from the slope of the tangent of indentation depth curve at maximum force, which was comparable with the modulus of elasticity of the material. For each material, a curve-fitted line out of 400 points was obtained.

\section{Data analysis}

Results were compared using one- and three-way ANOVA and Tukey's HSD post hoc test $(\mathbf{a}=0.05)$ with SPSS software (SPSS 14.0, SPSS Inc., Chicago, IL, USA). For analysis of strength data, Weibull analysis was additionally performed.

A common empirical expression for the cumulative probability of failure, $\mathrm{P}$, at applied stress, $\sigma$, is the following Weibull model ${ }^{16,17}$ :

$$
P_{f}\left(\sigma_{c}\right)=1-\exp \left[-\left(\frac{\sigma_{c}}{\sigma_{0}}\right)^{m}\right]
$$

where $\sigma_{c}$ is the measured strength, $m$ the Weibull modulus, and $\sigma_{0}$ the characteristic strength which was defined as strength at 0.63 probability of failure. The double logarithm of Equation (1) gives the following:

$$
\ln \ln \frac{1}{1-P}=m \ln \sigma_{c}-m \ln \sigma_{0}
$$

Equation (2)

By plotting $\ln \ln (1 /(1-\mathrm{P}))$ versus $\ln \boldsymbol{\sigma}_{\mathrm{c}}$, a straight line with an upward gradient $m$ was obtained, whereby intersection with the x-axis gave the logarithm of the characteristic strength ${ }^{16,17}$.

\section{RESULTS}

Flexural strength and modulus of elasticity

Figure 1 shows the results of the three-point flexural test in ascending order of the mean strength values. Hand-mixed systems were marked by an asterisk. Post hoc multiple pairwise comparisons with Tukey's HSD test $(p<0.05)$ delimitated four homogeneous subgroups, marked in the figure by brackets. Within a material, no significant differences were found between the hand-mixed and capsulated systems. Lowest flexural strengths were exhibited by the high-viscosity, conventional glass ionomers (14.9 - 34.4 MPa). Resin-modified glass ionomer Fuji Fil LC showed no significant differences when compared to Ionofil Molar, whereas Fuji II LC Improved and Vitremer reached the highest strength values. Similar results were observed also in terms of modulus of elasticity measured in flexural test (Fig. 2).

Weibull analysis of the strength data are summarized in Table 2. Besides the strength data of glass ionomer cements, Table 2 also presents the means strength values of four additional material categories _ compomers, hybrid, microfilled, and condensable (or "packable") composites - to serve as references (from the database of the Polyclinic for Restorative Dentistry and Periodontology, LudwigMaximilians University, Munich, Germany).

Figure 3 illustrates the Weibull analysis for the flexural strength data of Fuji IX, Ionofil Molar, and Fuji II LC Improved _ in both capsulated and handmixed forms. A crossover from the capsulated to the hand-mixed system caused a rise in the Weibull modulus, $\mathrm{m}$, in the case of conventional GICs, but a decrease for the resin-modified GIC material, Fuji II LC Improved. 


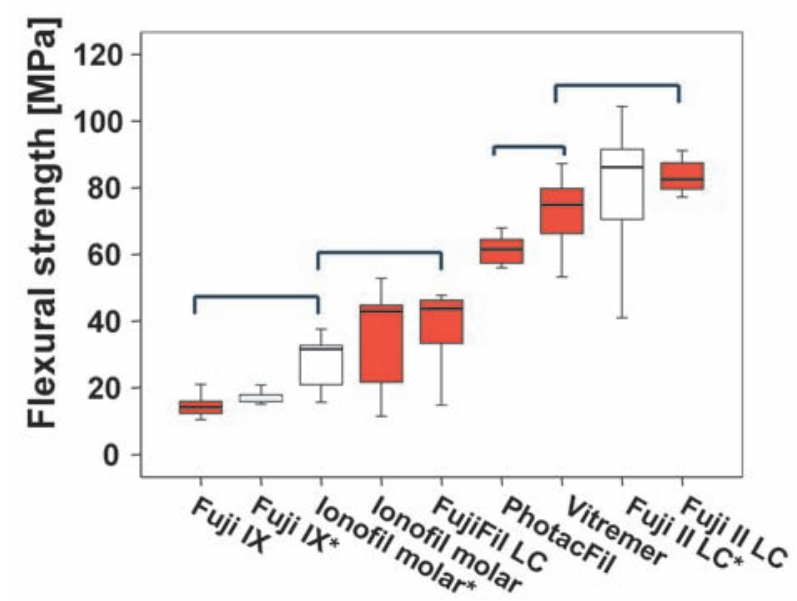

Fig. 1 Flexural strengths of tested materials. *: indicates hand-mixed system; statistically significant subgroups are indicated by brackets.

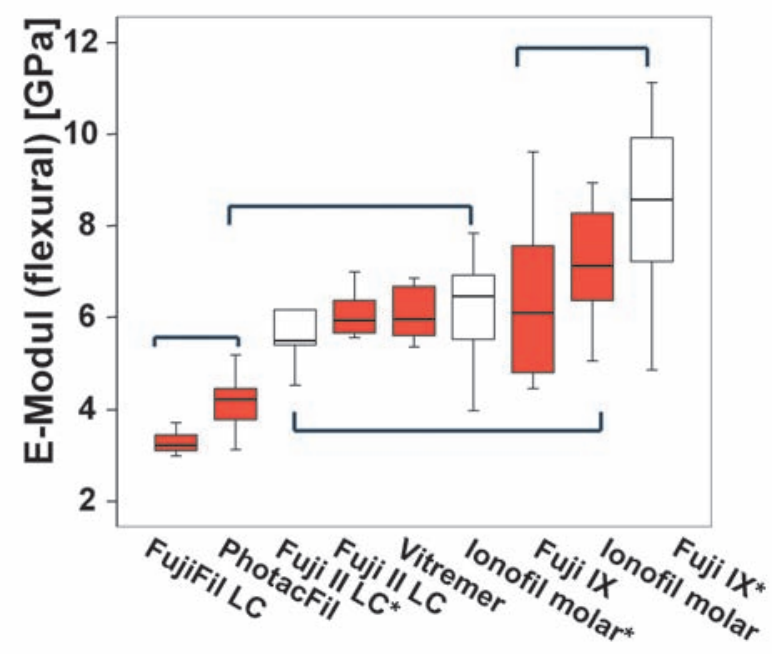

Fig. 2 Moduli of elasticity measured in flexural test. *: indicates hand-mixed system; statistically significant subgroups are indicated by brackets.

Table 2 Mean strength $\sigma$, Weibull parameter $m$, characteristic strength $\sigma_{0}$, and correlation of the straight line $\mathrm{R}^{2}$ for the bending, diametric tensile and compressive strengths. *: indicates hand-mixed system.

In addition, the means of four material categories _ compomers, hybrid, microfilled, and condensable (or "packable") composites - were used as references (from the database of the Polyclinic for Restorative Dentistry and Periodontology, Ludwig-Maximilians University, Munich, Germany)

\begin{tabular}{|c|c|c|c|c|c|c|c|c|c|c|c|c|}
\hline & \multicolumn{4}{|c|}{ Frexural } & \multicolumn{4}{|c|}{ diam.-tensile } & \multicolumn{4}{|c|}{ compressive } \\
\hline & $\sigma$ & $\mathrm{m}$ & $\sigma_{0}$ & $\mathrm{R}^{2}$ & $\sigma$ & $\mathrm{m}$ & $\sigma_{0}$ & $\mathrm{R}^{2}$ & $\sigma$ & $\mathrm{m}$ & $\sigma_{0}$ & $\mathrm{R}^{2}$ \\
\hline Fuji IX* & 16.4 & 7.1 & 17.6 & 0.88 & 11.5 & 4.3 & 12.7 & 0.97 & 83.6 & 2.1 & 94.7 & 0.95 \\
\hline Fuji IX & 14.9 & 4.5 & 16.3 & 0.9 & 12.0 & 4.4 & 13.2 & 0.95 & 99.0 & 6.3 & 106.3 & 0.94 \\
\hline Ionofil molar* & 28.2 & 3.7 & 31.5 & 0.93 & 9.4 & 4.7 & 10.3 & 0.90 & 78.8 & 4.8 & 86.1 & 0.92 \\
\hline Ionofil molar & 34.4 & 1.7 & 36.5 & 0.9 & 10.0 & 4.0 & 11.1 & 0.91 & 87.0 & 2.8 & 102.7 & 0.86 \\
\hline Fuji ॥ LC* & 78.2 & 3.6 & 87.6 & 0.88 & 18.9 & 7.7 & 20.1 & 0.97 & 165.4 & 13.7 & 171.6 & 0.98 \\
\hline Fuji ॥ LC & 83.1 & 21.6 & 85.2 & 0.9 & 20.7 & 11.0 & 21.7 & 0.91 & 156.6 & 15.5 & 161.8 & 0.96 \\
\hline Photac Fil & 59.8 & 7.5 & 63.7 & 0.83 & 16.9 & 11.4 & 17.6 & 0.93 & 143.0 & 29.1 & 145.6 & 0.95 \\
\hline Vitremer & 71.0 & 5.4 & 77.1 & 0.93 & 18.9 & 6.3 & 20.3 & 0.97 & 146.5 & 19.4 & 150.5 & 0.94 \\
\hline FujiFil LC & 39.1 & 3.1 & 44.6 & 0.84 & 14.3 & 7.0 & 15.3 & 0.99 & 116.0 & 19.5 & 119.1 & 0.92 \\
\hline Compomers & \multicolumn{4}{|c|}{$\sigma=94.2(32.0)$} & \multicolumn{4}{|c|}{$\sigma=33.2(9.5)$} & \multicolumn{4}{|c|}{$\sigma=217.0(52.2)$} \\
\hline Microfiled Composite & \multicolumn{4}{|c|}{$\sigma=75.6(11.8)$} & \multicolumn{4}{|c|}{$\sigma=23.0(2.7)$} & \multicolumn{4}{|c|}{$\sigma=258.5(37.2)$} \\
\hline Packable Composite & \multicolumn{4}{|c|}{$\sigma=108.8(28.9)$} & \multicolumn{4}{|c|}{$\sigma=34.1(8.2)$} & \multicolumn{4}{|c|}{$\sigma=217.0$} \\
\hline Hybrid Composite & \multicolumn{4}{|c|}{$\sigma=124.0(22.2)$} & \multicolumn{4}{|c|}{$\sigma=31.4(7.0)$} & \multicolumn{4}{|c|}{$\sigma=225.7(67.6)$} \\
\hline
\end{tabular}


Diametric tensile strength

In terms of diametric tensile strength, resin-modified GICs exhibited higher strength values than the conventional GICs (Fig. 4). Between capsulated and hand-mixed systems of a material, the differences were not significant. However, while Weibull statistics showed low differences in the Weibull parameter, $\mathrm{m}$, for conventional GICs Ionofil Molar and Fuji IX, an increase was observed for Fuji II LC Improved in capsulated form (Table 2).

In terms of compressive strength, a larger dispersion of strength data was registered for conventional GICs, whereas resin-modified GICs showed higher values (Fig. 5). Similarly, differences between the capsulated and hand-mixed systems of the same material were found to be insignificant.
Statistical analysis of the mechanical properties A nonparametric Kendall's tau-b correlation analysis of the strengths measured in all three loading tests showed that flexural strength had a significantly high correlation with compressive strength (0.70) and diametric tensile strength (0.70). Besides, the correlation between compressive and diametric tensile strengths (0.76) was also significant.

A three-way ANOVA with the primary factors "test type", "sample volume", and "material" showed that these factors, as well as their interaction products, had a significant influence on strength. Highest effect was exerted by "test type" and "sample volume" (eta-squared $=0.91$ ), followed by "material" (0.68), whereas the interaction products of the effects were lower (0.45). Considering the sample

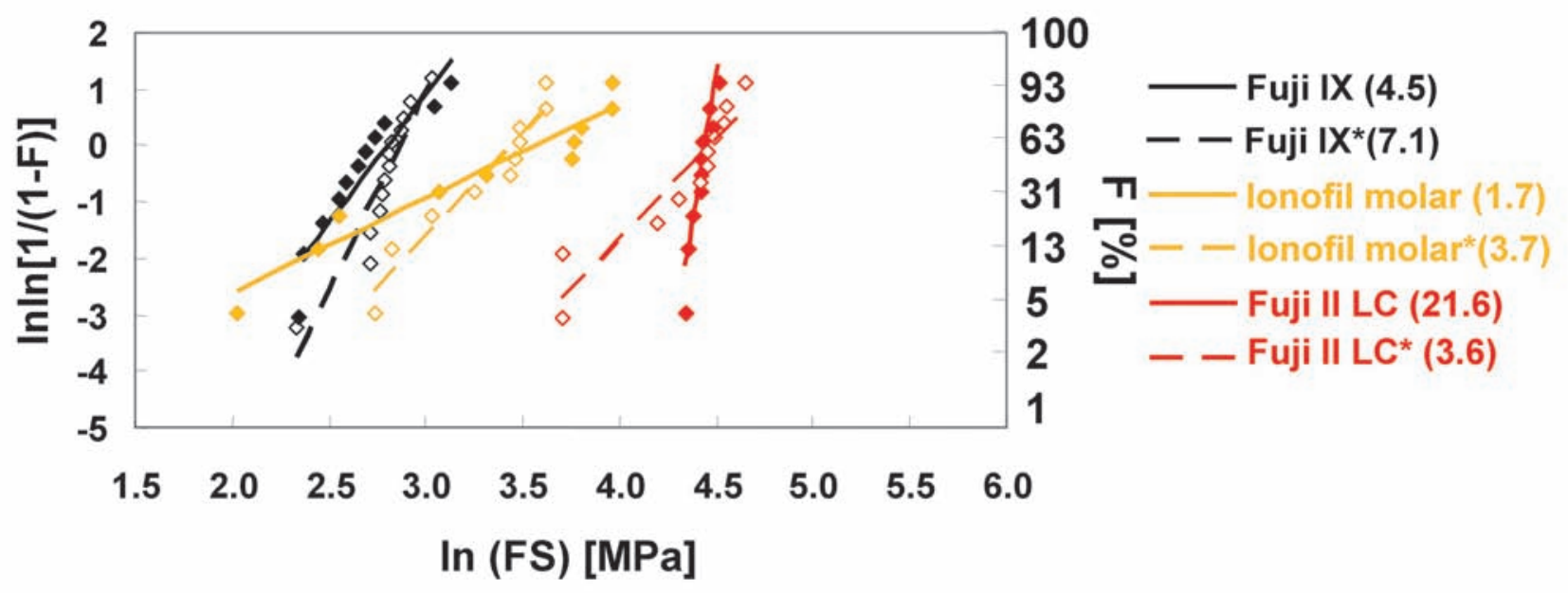

Fig. 3 Example of a Weibull analysis concretized for Fuji IX, Ionofil Molar, and Fuji II LC Improved in both forms - capsulated and hand-mixed systems. The Weibull modulus, m (gradient), is indicated in parentheses.

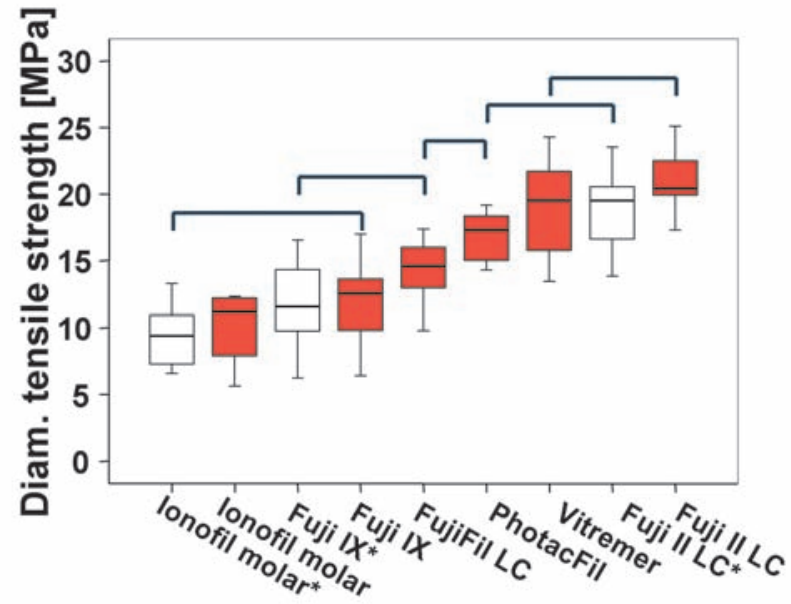

Fig. 4 Diametric tensile strengths of tested materials. *: indicates hand-mixed system; statistically significant subgroups are indicated by brackets.

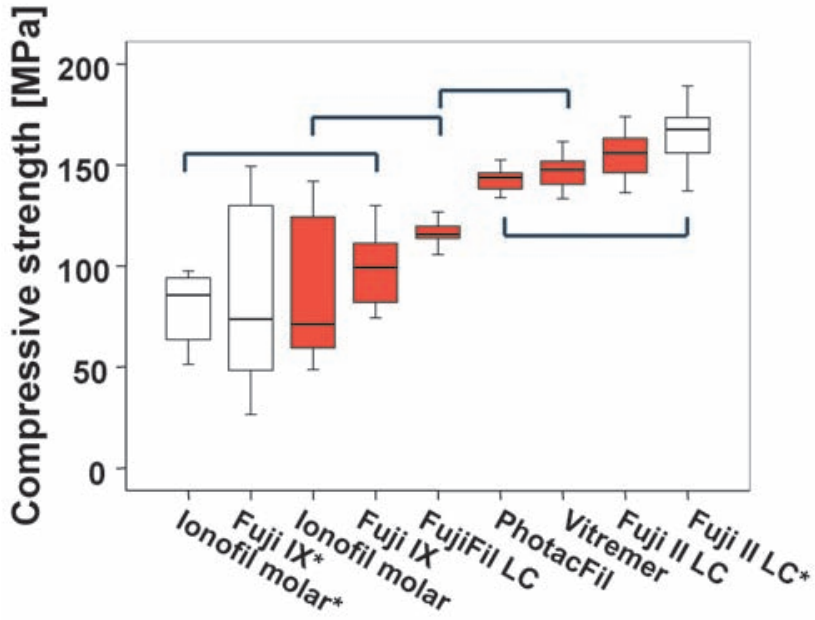

Fig. 5 Compressive strengths of tested materials. *: indicates hand-mixed system; statistically significant subgroups are indicated by brackets. 

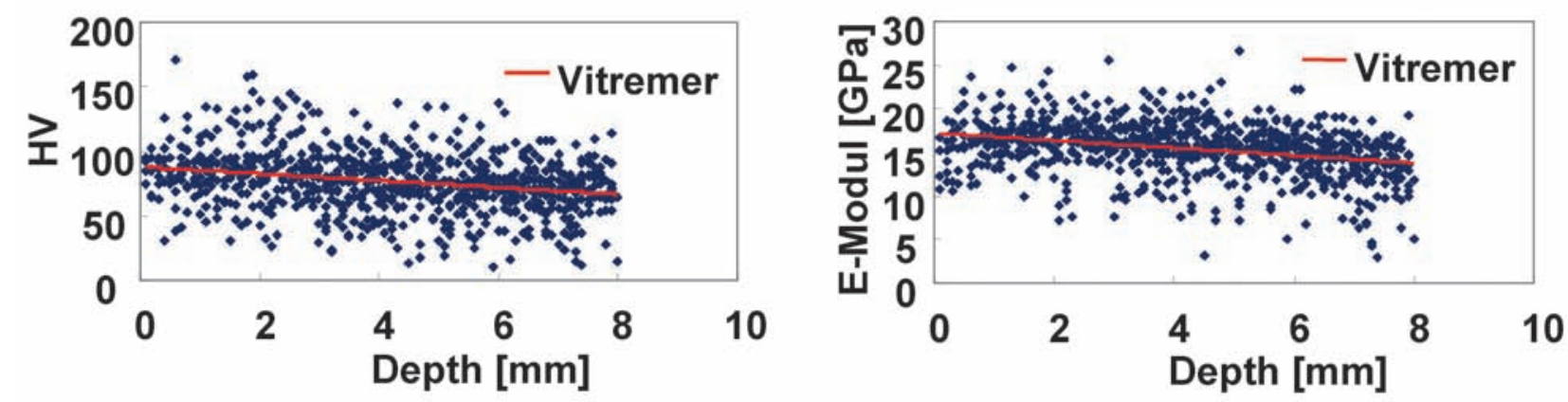

Fig. 6 Variation of hardness and modulus of elasticity with depth as exemplified in Vitremer.

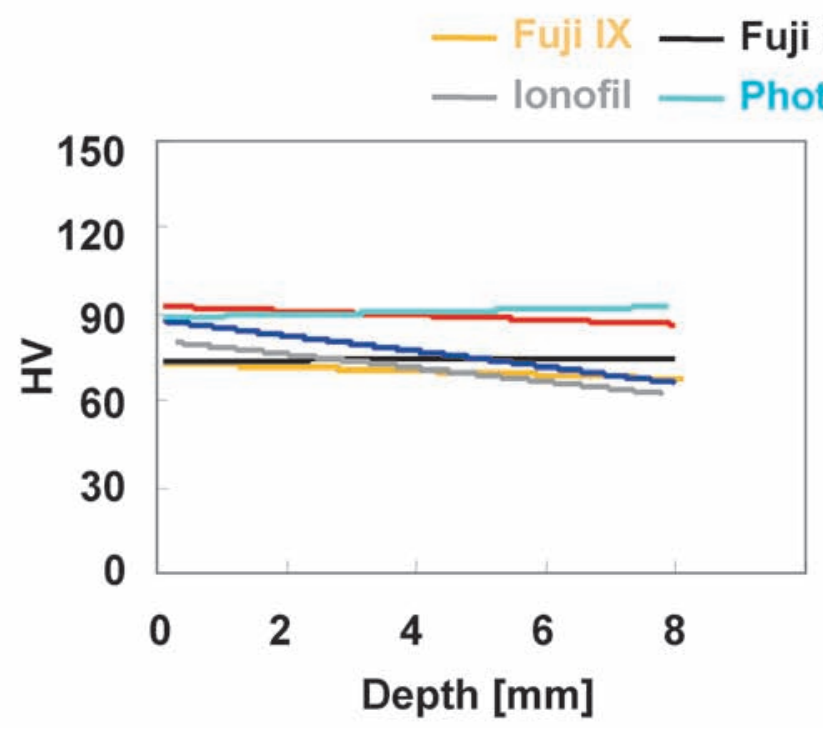

Fig. 7 Mean curves of variation of hardness and modulus of elasticity with depth.

geometries, sample volume increased from flexural test $\left(\mathrm{V}=64.0 \mathrm{~mm}^{3}\right)$ through diametric tensile test $\left(\mathrm{V}=84.8 \mathrm{~mm}^{3}\right)$ to compressive test $\left(\mathrm{V}=108.5 \mathrm{~mm}^{3}\right)$.

Variation of hardness and modulus of elasticity with depth

Figure 6 presents the variation of hardness and modulus of elasticity with depth as exemplified in Vitremer. A large dispersion of the measured data was noticed for all tested materials. A curve-fitted line was plotted for each material (Fig. 7) to examine the gradients of hardness and modulus of elasticity with depth.

\section{DISCUSSION}

The present study analyzed the behavior of six glass ionomer cements - two conventional and four resinmodified - under different loading conditions. In addition, this study also investigated if the form in which the materials were supplied by the manufacturers _ as a powder-liquid hand-mixed system or in a capsulated system - affected the mechanical properties of the materials.

The evaluated glass ionomer cements showed significant differences in the measured characteristics. Mean flexural strength varied between 14.9 and 83.1 $\mathrm{MPa}$, diametric tensile strength between 9.4 and 20.7 MPa, and compressive strength between 78.8 and 165.4 MPa. Strengths of the materials evaluated showed widely dispersed results $(>15 \%)$ connected to the cause of fracture, since dispersion of strength is related to the dispersion of failure sizes ${ }^{16,17)}$. It should be mentioned that means and standard deviations for the strength of inhomogeneous materials do not offer sufficient information ${ }^{16,17)}$. Hence, in addition to ANOVA, a Weibull analysis is necessary for a better understanding of material behavior.

The Weibull modulus $m$ (or Weibull parameter) is a measure of the degree of dispersion of strength data $^{16,17)}$; in other words, it shows how homogeneous a material is. The probability of fracture increases with increased material volume. Transposed to a clinical situation, it would mean that at identical 
stress, large fillings will fail sooner than small fillings made of the same material. Further, with reference to Equation (1), the faster the increase in fracture probability $\mathrm{P}$, the lower is the degree of dispersion $\mathrm{m}$. In other words, high $\mathrm{m}$ values are to be preferred. In the present study, conventional glass ionomers were lower than resin-modified glass ionomers not only in strength values, but also in Weibull modulus, $\mathrm{m}$, generally (Table 2). In a clinical situation, this would mean earlier fractures of fillings made of conventional glass ionomers. In this connection, light-cured glass ionomers performed better than the conventional glass ionomers in all tested conditions. Therefore, considering the Weibull parameter of the bending test, Fuji II LC Improved seemed to be the most reliable material of this series. Indeed, the generally higher values of the Weibull parameter $\mathrm{m}$ in the compression test (Table 2) further confirmed the higher reliability of all resinmodified glass ionomers under compressive load.

Dependencies between tensile, bending, and compressive strengths were not similar for all tested materials. The following dependency ranges were found between the three measured strengths:

Tensile : Bending : Compressive strength $=1:[1.3-$ $4.2]:[7.3-9.0]$

whereby the extreme values were exhibited by Fuji II LC Improved (1: $4.2: 9.0$ ), showing a 9-fold higher compressive strength and a 4.2-fold higher flexural strength compared to the diametric tensile strength. At the other end of the spectrum, Fuji IX exhibited $1: 1.3: 7.3$ for DTS and bending strength results. Thus, within one material class, no clear dependency could be registered between the three tested strengths, attesting to the necessity of evaluating materials under different loading conditions and not to draw premature conclusions from simplified tests.

To date, the minimum strength values required for the survival of dental restorations have not been determined. According to ISO $4049^{15)}$, the bending strength of filling composites must exceed 50 $\mathrm{MPa}$. In our study, only the resin-modified glass ionomer cements - Fuji II LC Improved, Photac Fil, and Vitremer - met this value, and hence approximated the composite materials (Table 2).

As mentioned above, the dispersion of strength is related to the dispersion of failure sites ${ }^{16,17}$. Comparing the powder-liquid hand-mixed systems with the capsulated ones, the influence on mechanical properties seemed to stem from material property. Thus, even if differences in strength measured in all the tests were independent of the way in which the material was mixed, higher values of Weibull modulus $m$ were observed for the hand-mixed systems of conventional glass ionomer cements
(Table 2). With resin-modified glass ionomer cements, the capsulated system yielded a more homogeneous material - and consequently a higher reliability. A plausible explanation could be the viscosity and rheological behavior of the materials, which therefore meant that characterization of the materials is necessary.

Differences in Weibull parameter values for the same material are related to both the distribution and amount of defects ${ }^{16,17}$. In a $\mu$-CT analysis of cylindrical samples made of glass ionomers, Nomoto et $a l .{ }^{18)}$ showed that the mixing method had a significant effect on porosity, and that the nature, size, and number of bubbles were hardly dependent on material viscosity. Further, they detected more large bubbles in specimens mixed mechanically than by hand for the more fluid materials. In other words, the slower, hand-mixing procedure in which the material was spatulated helped to avoid large inclusions and might have also caused some air bubbles to collapse.

Microhardness and modulus of elasticity were found to be independent of the way in which the materials were mixed. This was largely due to the fact that these measurements were not influenced by big defects such as large voids, which would otherwise dramatically decrease the macroscopic strength. This assertion was further substantiated by considering the influence of the chemical composition of glass ionomers on mechanical properties. Regarding their macroscopic physical properties, the conventional glass ionomers were inferior to the light-cured glass ionomers. Conversely, the microhardness of all tested materials was comparable. Taken together, it could be suggested that whereas there was no clear dependency between the chemical composition of the glass ionomers and the tested mechanical properties, the defects seemed to assume the dominant role in influencing the final macroscopic mechanical properties.

Furthermore, the determinant hardening mechanism in the tested light-cured glass ionomers seemed to be the chemical hardening process, and not the light-curing process. This was because hardness and modulus of elasticity did not dramatically decrease with depth.

Although GICs generally show lower strength values than the composite materials (Table 2), their clinical performance in some situations is remarkable. Peumans et $a l .{ }^{19}$, in their review of several clinical studies on the performance of Class $\mathrm{V}$ cavities, concluded that glass ionomer cements exhibited the best clinical performance when compared with the adhesive fixed composites. 


\section{CONCLUSIONS}

In all macroscopic strength tests, the resin-modified glass ionomer cements performed significantly better than the high-viscosity, conventional glass ionomers. However, in microhardness evaluation, the differences were leveled out. In particular, the mechanical properties of RMGICs were comparable to those of microfilled and packable composites.

In the comparison of power-liquid hand-mixed system versus the capsulated system, the influence on mechanical properties seemed to stem from the material property. Tested conventional glass ionomers performed better when they were handmixed, whereas resin-modified glass ionomers fared better in the capsulated form.

\section{ACKNOWLEDGEMENTS}

The authors sincerely thank Mrs. Indra Njamaa for her help in sample preparation.

\section{REFERENCES}

1) Glasspoole EA, Erickson RL, Davidson CL. Effect of surface treatments on the bond strength of glass ionomers to enamel. Dent Mater 2002; 18: 454-462.

2) Hunt PR. Glass ionomers: the next generation. A summary of the current situation. $J$ Esthet Dent 1994; 6: 192-194.

3) Mount GJ. Buonocore Memorial Lecture. Glassionomer cements: past, present and future. Oper Dent 1994; 19: 82-90.

4) Wiegand A, Buchalla W, Attin T. Review on fluoride-releasing restorative materials - Fluoride release and uptake characteristics, antibacterial activity and influence on caries formation. Dent Mater 2007; 23: 343-362.

5) Naasan MA, Watson TF. Conventional glass ionomers as posterior restorations. A status report for the American Journal of Dentistry. Am J Dent 1998; 11: 36-45.
6) Mount GJ. Glass ionomers: a review of their current status. Oper Dent 1999; 24: 115-124.

7) Xie D, Brantley WA, Culbertson BM, Wang G. Mechanical properties and microstructures of glassionomer cements. Dent Mater 2000; 16: 129-138.

8) de Gee AJ, van Duinen RN, Werner A, Davidson CL. Early and long-term wear of conventional and resinmodified glass ionomers. J Dent Res 1996; 75: 16131619.

9) Cattani-Lorente MA, Godin C, Meyer JM. Mechanical behavior of glass ionomer cements affected by long-term storage in water. Dent Mater 1994; 10: 37-44.

10) Williams JA, Billington RW, Pearson GJ. The comparative strengths of commercial glass-ionomer cements with and without metal additions. Br Dent J 1992; 172: 279-282.

11) Frankenberger R, Sindel J, Kramer N. Viscous glass-ionomer cements: a new alternative to amalgam in the primary dentition? Quintessence Int 1997; 28: 667-676.

12) Frencken JE, Taifour D, Van't Hof MA. Survival of ART and amalgam restorations in permanent teeth of children after 6.3 years. J Dent Res 2006; 85: 622-626.

13) Burgess J, Norling B, Summit J. Resin ionomer restorative materials: the new generation. $\mathrm{J}$ Esthet Dent 1994; 6: 207-215.

14) Sidhu SK, Watson TF. Resin-modified glass ionomer materials. A status report for the American Journal of Dentistry. Am J Dent 1995; 8: 59-67.

15) ISO 4049 : 1988 + Technische Korrektur 1 : 1992, Deutsche Fassung EN 24049 : 1993: Zahnheilkunde, F̈̈jllungskunstsftoffe.

16) SJ Schneider. Engineered materials handbook, ASM International, USA, 1991, pp.703-707.

17) Weihull W. A statistical distribution function of wide applicability. J Appl Mech 1951; 18: 290-293.

18) Nomoto R, Komoriyama M, McCabe JF, Hirano S. Effect of mixing method on the porosity of encapsulated glass ionomer cement. Dent Mater 2004; 20: 972-978.

19) Peumans M, Kanumilli P, De Munck J, Van Landuyt K, Lambrechts P, Van Meerbeek B. Clinical effectiveness of contemporary adhesives: a systematic review of current clinical trials. Dent Mater 2005; 21: 864881. 